University of Nebraska - Lincoln

DigitalCommons@University of Nebraska - Lincoln

Other Publications in Zoonotics and Wildlife

Disease

Wildlife Disease and Zoonotics

1993

\title{
Infection with a Ratborne Hantavirus in US Residents Is Consistently Associated with Hypertensive Renal Disease
}

\author{
Gregory E. Glass \\ Johns Hopkins School of Medicine \\ Alan J. Watson \\ Johns Hopkins School of Medicine \\ James W. LeDuc \\ Centers for Disease Control, Atlanta \\ Gabor D. Kelen \\ Johns Hopkins School of Medicine \\ Thomas C. Quinn \\ Johns Hopkins School of Medicine \\ See next page for additional authors
}

Follow this and additional works at: https://digitalcommons.unl.edu/zoonoticspub

Part of the Veterinary Infectious Diseases Commons

Glass, Gregory E.; Watson, Alan J.; LeDuc, James W.; Kelen, Gabor D.; Quinn, Thomas C.; and Childs, James E., "Infection with a Ratborne Hantavirus in US Residents Is Consistently Associated with Hypertensive Renal Disease" (1993). Other Publications in Zoonotics and Wildlife Disease. 50. https://digitalcommons.unl.edu/zoonoticspub/50

This Article is brought to you for free and open access by the Wildlife Disease and Zoonotics at DigitalCommons@University of Nebraska - Lincoln. It has been accepted for inclusion in Other Publications in Zoonotics and Wildlife Disease by an authorized administrator of DigitalCommons@University of Nebraska - Lincoln. 
Authors

Gregory E. Glass, Alan J. Watson, James W. LeDuc, Gabor D. Kelen, Thomas C. Quinn, and James E. Childs 


\title{
Infection with a Ratborne Hantavirus in US Residents Is Consistently Associated with Hypertensive Renal Disease
}

\author{
Gregory E. Glass, Alan J. Watson, James W. LeDuc,* \\ Gabor D. Kelen, Thomas C. Quinn, and James E. Childs*
}

\begin{abstract}
Department of Immunology and Infectious Diseases, Johns Hopkins University School of Hygiene and Public Health, and Department of Nephrology and Divisions of Emergency Medicine and of Infectious Diseases, Johns Hopkins School of Medicine, Baltimore; Disease Assessment Division, Department of Epidemiology, US Army Medical Research Institute of Infectious Diseases, Fort Detrick; Laboratory of Immunoregulation, National Institute of Allergy and Infectious Diseases, National Institutes of Health, Bethesda, Maryland
\end{abstract}

\begin{abstract}
A survey of 8080 subjects was conducted in Baltimore, examining the association between infection with hantaviruses and renal disease. Two groups $(N=6060)$ with no known risk factors were selected to establish a baseline antibody prevalence. Overall, antibody prevalence was $0.25 \%$. Seroprevalence increased with age, without sex- or race-related differences. Patients with proteinuria showed the same patterns of infection but were more commonly seropositive (1.46\%) than the reference group $(\mathrm{OR}, 3.23 ; \mathrm{P}<.05)$. Infection among dialysis patients with end-stage renal disease was $2.76 \%$, significantly higher than in the reference group $(\mathrm{OR}, 5.03 ; \mathrm{P}<.05)$. In the proteinuria and the dialysis groups, hantavirus infection was consistently associated with a diagnosis of hypertensive renal disease. The association was unrelated to other chronic renal disease diagnoses. Overall, $6.5 \%$ of patients with end-stage renal disease due to hypertension were seropositive for a hantavirus. These data suggest that hantavirus infection is associated with hypertensive renal disease.
\end{abstract}

Hantaviruses (family Bunyaviridae), the etiologic agents of hemorrhagic fever with renal syndrome (HFRS), are distributed worldwide, primarily in rodent reservoirs [1]. HFRS varies in severity depending on the specific infecting hantavirus but is typically defined by fever, transient renal dysfunction, and, less commonly, hemorrhage. Although primarily recognized from Korea, China, Russia, and Scandinavia, HFRS now is being identified from many countries in Europe and Asia not previously thought to be endemic for these viruses [2,3].

Studies in North America have led to the isolation of han-

Received 22 June 1992; revised 20 October 1992

Presented in part: 40th annual meeting of the American Society of Tropical Medicine and Hygiene, Boston, December 1991 (abstract 400).

Informed consent was given by participants. The protocols and informed consent forms were reviewed and approved by scientific and institutional review boards at the US Army Medical Research Institute of Infectious Diseases and Johns Hopkins Medical Institutions.

Views of the authors do not purport to reflect the positions of the Department of the Army or Department of Defense.

Financial support: US Army Medical Research and Development Command (DAMD17-87-C-7101, DAMD17-89-C-9093).

Reprints or correspondence: Dr. Gregory E. Gurri Glass, Dept. of Immunology and Infectious Diseases, Johns Hopkins University School of Hygiene and Public Health, 615 N. Wolfe St., Baltimore, MD 21205.

* Present affiliations: Microbiology and Immunology Support Services, World Health Organization, Geneva (J.W.L.); Viral and Rickettsial Zoonoses Branch, Division of Viral and Rickettsial Diseases, Centers for Disease Control, Atlanta (J.E.C.).

The Journal of Infectious Diseases 1993;167:614-20 (C) 1993 by The University of Chicago. All rights reserved. 0022-1899/93/6703-0014\$01.00 taviruses from several species of rodents [4-8], and human serologic surveys have demonstrated antibodies in geographically and occupationally diverse groups, ranging from foresters to shipyard workers [7, 9-12]. In the United States, studies using plaque reduction neutralization (PRN) tests with a library of representative hantaviruses have clearly linked antibody in humans from Baltimore to domestically acquired infection with a strain of Seoul virus, a Norway rat (Rattus norvegicus)-associated hantavirus $[10,11]$.

Even though human infection with hantaviruses has been demonstrated in the United States, there have been no documented cases of HFRS nor any descriptions of disease accompanying seroconversion to a hantavirus. A single possible case of HFRS due to Leakey virus, a house mouse (Mus musculus)-associated hantavirus, has been reported but not confirmed [8]. The failure to recognize HFRS in the United States has led to the hypothesis that domestic strains of hantavirus may produce asymptomatic infections or atypical disease [13] or that human exposures to these viruses (or contacts with their rodent reservoirs) occur less often than in other countries.

Despite the absence of acute disease, there is epidemiologic evidence that infection with hantaviruses, even where endemic HFRS is not recognized, is associated with chronic renal disease. In Baltimore, infection with a ratborne hantavirus, as evidenced by neutralizing antibody, was associated with hypertensive renal disease and hypertension among inner-city hospital patients with proteinuria [14]. Although recovery from HFRS is usually believed to be complete, reports from locations endemic for the disease also indicate 
that some percentage of patients do suffer long-term sequelae [15-18].

This study was designed to investigate intensively the epidemiology of locally acquired hantavirus infections in Baltimore and to examine the association of infection with chronic renal disease. We established baseline antibody prevalence to the local Seoul virus strain, Baltimore rat virus, in a large sample of city residents. Then we prospectively monitored selected inpatients at a large inner-city hospital for antibodies to hantaviruses. Finally, we sampled renal dialysis patients from four hemodialysis units within the city and examined the association between hantavirus antibody and specific diagnoses of renal disease, with the a priori prediction that seropositivity would be positively associated with hypertensive renal disease [14].

\section{Materials and Methods}

Serologic surveys. Four groups were selected for study; two had no known risk factors for exposure to hantaviruses except residing in a city that had infected rats $[11,19]$. These two groups, described below, served as a reference sample to provide background antibody prevalence levels for Baltimore.

The third group was drawn from patients at Johns Hopkins Hospital (JHH) who received quantitative urine total protein (UTP) tests. Proteinuria was used as an inclusion criterion, as it is a consistent laboratory finding in cases of HFRS regardless of the causative hantavirus [20-22]. As proteinuria also serves as a general marker of renal dysfunction, this group was used to evaluate the association between hantavirus infection and underlying diagnoses of renal disease.

The fourth group consisted of patients from inner-city Baltimore with end-stage renal disease on maintenance hemodialysis. This group was selected to examine the hypothesis that hantavirus infection is associated with specific chronic renal sequelae, especially hypertensive renal disease [14].

Sexually transmitted disease (STD) group. Sera were gathered from 2660 patients visiting a Baltimore STD clinic from March 1985 through March 1988. Interviews were conducted twice weekly from consecutive willing individuals. Information on age, sex, race, and residence were obtained from a short questionnaire given orally. Details of data collection procedures and serologic results from a specific subsample $(N=1180)$ of the STD group were reported previously [11]. Data from the entire STD group, including the previously reported subsample, are included here as part of the larger reference sample.

JHH Emergency Department group. Sera were obtained from 3400 patients as part of an AIDS study conducted by the JHH Department of Emergency Medicine (ER). Individuals were enrolled from June to August 1988. Information was gathered on age, sex, race, and zip code of residence. Some sampling weight was given to the younger age groups. Details of the procedures are described elsewhere [23].

JHH proteinuria group. Sera were obtained from $1766 \mathrm{pa}^{-}$ tients whose physicians requested 24-h UTP tests and blood chemistry panels from the Blood Chemistry Department at JHH. Samples were gathered from January 1986 to May 1990 from all patients with proteinuria $>250 \mathrm{mg} / 24 \mathrm{~h}$ for whom serum samples were available. Also, the first 2 subjects with proteinuria $<150 \mathrm{mg} / 24 \mathrm{~h}$ from a randomly selected day in each week were chosen to form an internal, second reference group to assess the association between hantavirus infection and proteinuria.

Information was obtained on age and sex for all patients. However, racial status was not generally available and could be obtained only by reviewing patients' charts. Medical histories were obtained from all seropositive and a subsample of age- and sexmatched seronegative patients (see below) by researchers blinded for serologic status. Details of the procedures and preliminary findings on the association between hantavirus antibody and hypertensive renal disease are described elsewhere [14].

Dialysis group. Sera were obtained from 1988 to 1991 from 254 patients with end-stage renal disease. All patients $(N=328)$ in four hemodialysis units serving the inner-city area of Baltimore were eligible for the study. Participants provided a blood sample and information on age, sex, race, and residence by zip code.

The International Classification of Diseases (ICD) code for the diagnosis of underlying renal disease was obtained from patient records, before serologic testing, and cross-checked with the patient's primary health care provider. ICD codes were aggregated into diagnostic groups for underlying renal disease [24]. These groups included hypertensive renal disease (ICD codes 401 . and 403.), diabetic renal disease (codes 250., 583.71, and 583.81 if diabetes was specified as the underlying cause of disease), drug nephrotoxicity (code 584.5), glomerulosclerosis (code 581.), glomerulonephritis (code 582.), nephrolithiasis (code 592.), polycystic kidney disease (code 753.), and other.

Information on dialysis patients who did not participate in this study was provided in aggregate without identifiers. These data were used to check for participation bias on the basis of demographic and diagnostic variables.

Serologic assays. Hantavirus infection was determined serologically. Initially, all sera were screened at 1:100 dilutions for IgG to prototype Hantaan virus (strain 76-118) by ELISA [25]. Antigen was derived from Vero-E6-infected cell lysates as described previously [26]. Uninfected Vero-E6 cell lysates were included in duplicate wells as controls. Samples with optical densities $>3$ SD above the mean of 3 negative control sera included on each plate were tested further.

Specific antibody in each positive screen was confirmed by PRN assays using Baltimore rat virus, Hantaan virus, and Prospect Hill virus, a vole-associated hantavirus isolated from Microtus pennsylvanicus captured in Frederick, Maryland [6]. Differential neutralization titers, which vary by 4 - to 32 -fold among homologous and heterologous viruses [10,25], were used to identify the particular infecting hantavirus. A neutralization titer of $\geqslant 1: 10$ for sera that reduced plaque formation by $\geqslant 80 \%$ was considered positive.

Data analysis. Analyses were done with either SAS [27] or BMDP [28] statistical software systems. Descriptive analyses were done for all variables, and initial comparisons were made by contingency table, with calculations of odds ratios (OR) and 95\% confidence intervals (CI) as appropriate. Mantel-Haenszel weighted ORs were used to compare age-stratified prevalence data between various groups. 
For analyses exploring the association of hantavirus antibody and chronic disease in the dialysis group, all frequency variables were tested with Fisher's exact test or as ORs with CI. Twotailed tests were used in all comparisons.

Conditional logistic regression analysis was done on the $\mathrm{JHH}$ proteinuria group with matched seropositive (cases) and seronegative patients (controls). Patients were matched for age (within 3 years) and sex, with 5 randomly selected controls per case. This analysis included 15 cases that were previously described and analyzed by univariate methods [14]. Information was obtained on race, residence (subsequently coded as city resident or not), current and previous occupation, hospital unit, reason for admission, and the occurrence of any chronic diseases.

Preliminary study [14] had shown that the only variables that differed between infected and uninfected individuals were the presence of hypertensive renal disease, hypertension, and stroke. Therefore, the initial regression model included these variables as well as race. Other clinical and demographic variables were subsequently added and were kept in the model only if they significantly improved the fit of the model to the outcome of serologic status.

All demographic and clinical data from the $\mathrm{JHH}$ proteinuria patients were obtained by two reviewers independently screening medical charts without prior knowledge of the serologic status of the patients. All demographic and diagnostic data were obtained from the dialysis group before serologic testing. Statistical examination of primary diagnoses underlying chronic renal disease for both the JHH proteinuria and dialysis groups was done after grouping ICD codes into four categories: no chronic renal disease, diabetes mellitus, hypertension, and other.

\section{Results}

\section{Seroepidemiology}

Reference population. Among the two groups selected to establish background antibody prevalence in Baltimore, 11 patients $(0.32 \%)$ from the JHH ER and 4 patients $(0.15 \%)$ from the STD clinic were seropositive to a hantavirus, as confirmed by PRN tests. All had highest neutralizing titers to Baltimore rat virus, suggesting exposure to the local rat-associated hantavirus. There were no statistically significant differences in prevalence between the ER and STD groups by race, sex, or age, stratified by 20-year age groups (table 1).

On the basis of similarities of low antibody prevalence across all demographic classifications, the two groups were combined into a single reference group for further analyses. Infection patterns in the remaining groups were compared to those of the reference group. However, as a more conservative test, comparisons also were done using only the ER group as a standard. There were no differences in the results using the entire reference group or only the ER group, so results of the reference group comparisons are shown.

In the reference group, seroprevalence increased from $0.11 \%$ in persons $<21$ years old $(n=1839)$ to $0.70 \%$ in those $>60(n=284$; table 2$)$. There were no differences in sero-
Table 1. Prevalence of neutralizing antibody to Baltimore rat virus, a strain of Seoul virus, in patients visiting Johns Hopkins Emergency Medicine Department (ER) and a sexually transmitted disease clinic (STD) in Baltimore, 1985-1989.

\begin{tabular}{llllll}
\hline & \multicolumn{2}{c}{ ER } & & \multicolumn{2}{c}{ STD } \\
\cline { 2 - 3 } \cline { 5 - 6 } Variable & $\begin{array}{c}\text { No. } \\
\text { positive/total }\end{array}$ & $\begin{array}{c}\% \\
\text { positive }\end{array}$ & & $\begin{array}{c}\text { No. } \\
\text { positive/total }\end{array}$ & $\begin{array}{c}\% \\
\text { positive }\end{array}$ \\
\hline Race & & & & \\
$\quad$ African-American & $9 / 2474$ & 0.36 & & $4 / 2563$ & 0.16 \\
Caucasian & $2 / 897$ & 0.22 & & $0 / 83$ & 0 \\
$\quad$ Other & $0 / 29$ & 0 & & $0 / 14$ & 0 \\
Sex* & & & & \\
Male & $7 / 1820$ & 0.38 & & $4 / 1878$ & 0.21 \\
Female & $4 / 1578$ & 0.25 & & $0 / 782$ & 0 \\
Age, years & & & & 0 \\
$\quad<21$ & $2 / 1067$ & 0.19 & & $0 / 772$ & 0 \\
$21-40$ & $4 / 1663$ & 0.24 & & $4 / 1775$ & 0.23 \\
$41-60$ & $3 / 399$ & 0.75 & & $0 / 100$ & 0 \\
$>60$ & $2 / 271$ & 0.74 & & $0 / 13$ & 0 \\
\hline
\end{tabular}

* Data missing for 2 subjects.

prevalence associated with race $(0.26 \%$ African-Americans vs. $0.20 \%$ all others; OR, 1.32 ; CI, $0.28-8.48)$ or sex $(0.30 \%$ male subjects vs. $0.17 \%$ female subjects; OR, 1.76; CI, 0.52-6.54).

JHH proteinuria group. Antibody prevalence was $1.46 \%$ among patients in the $\mathrm{JHH}$ proteinuria population whose proteinuria $>250 \mathrm{mg} / 24 \mathrm{~h}(n=1507) ; 22$ of these patients were seropositive to a hantavirus, and all had highest neutralizing titers to Baltimore rat virus. Seroprevalence also increased with age in this group from zero in those $<21$ years old to $2.21 \%$ in those $>60$ (table 2). ORs of seroprevalence based on age-stratified comparisons between the JHH proteinuria population and the reference group ranged from 2.69 to 3.68 and were consistently elevated over all strata. Although statistical significance in each age stratum was precluded by small numbers of seropositive subjects, there was a significant overall increase in antibody prevalence in the JHH proteinuria group when adjusted for age (MantelHaenszel weighted OR, 3.23; CI, 1.35-7.44).

As with the reference group, there was no association between hantavirus infection and sex (1.27\% male subjects vs. $1.59 \%$ female subjects; OR, 0.80; CI, 0.30-2.04). There was a higher proportion of seropositive subjects among AfricanAmericans than among other races when seropositive subjects were compared with matched controls (see below); however, the difference was not statistically significant (OR, 3.56; CI, 0.92-16.06).

In total, $259 \mathrm{JHH}$ inpatients were sampled who had UTP tests but showed proteinuria $<150 \mathrm{mg} / 24 \mathrm{~h}$. In this second, internal reference group, only 1 patient was seropositive for hantavirus. Infection was with BRV. The level of association between hantavirus antibody and the occurrence of protein- 
Table 2. Race, sex, and age-associated seroprevalence to Baltimore rat virus based on neutralization antibody tests in reference, proteinuria, and dialysis groups.

\begin{tabular}{|c|c|c|c|c|c|}
\hline \multirow[b]{2}{*}{ Variable } & \multirow{2}{*}{$\begin{array}{l}\text { Reference } \\
\text { group, } \\
\% \text { positive } \\
(n)^{*}\end{array}$} & \multicolumn{2}{|c|}{ Proteinuria } & \multicolumn{2}{|c|}{ Dialysis } \\
\hline & & $\begin{array}{c}\% \text { positive } \\
(n)\end{array}$ & OR & $\begin{array}{c}\% \text { positive } \\
(n)\end{array}$ & OR \\
\hline \multicolumn{6}{|l|}{ Race } \\
\hline African-American & $0.26(5037)$ & - & - & $3.37(208)$ & 13.46 \\
\hline Other & $0.20(1023)$ & - & - & $0.00(46)$ & - \\
\hline \multicolumn{6}{|l|}{ Sex } \\
\hline Male & $0.30(3698)$ & $1.27(628)$ & 4.32 & $2.72(110)$ & 9.40 \\
\hline Female & $0.17(2360)$ & $1.59(879)$ & 9.53 & $2.78(144)$ & 16.83 \\
\hline \multicolumn{6}{|l|}{ Age, years } \\
\hline$<21$ & $0.11(1839)$ & $0.0(161)$ & - & - & - \\
\hline $21-40$ & $0.23(3438)$ & $0.62(481)$ & 2.69 & $1.92(52)$ & 8.41 \\
\hline $41-60$ & $0.60(499)$ & $2.18(367)$ & 3.68 & $0.94(106)$ & 1.56 \\
\hline$>60$ & $0.70(284)$ & $2.21(498)$ & 3.18 & $5.43(92)$ & 8.10 \\
\hline Overall & $0.25(6060)$ & $1.46(1507)$ & 3.23 & $2.80(250)$ & 5.03 \\
\hline
\end{tabular}

NOTE. Proteinuria group includes only patients with urine total protein $>250 \mathrm{mg} / 24 \mathrm{~h}$. Odds ratios (ORs) use appropriate age class from reference group for comparison. Overall ORs are weighted Mantel-Haenszel ORs. -, not calculated due to lack of data.

* Includes total figures from sexually transmitted disease and Johns Hopkins Emergency Medicine Department groups from table 1 .

uria within the hospital population (OR, 3.82; CI, 0.557.65 ) was similar to that between the JHH proteinuria group and the external reference group.

Hemodialysis group. Among patients using hemodialysis because of end-stage renal disease, hantavirus antibody prevalence was $2.76 \%(7 / 254)$. All patients had highest neutralizing antibody titers to Baltimore rat virus. Seroprevalence tended to increase by age stratum, ranging from $1.92 \%$ in those 21-40 years old (there were no patients sampled in the $<21$ years group) to $5.43 \%$ in those $>60$ (table 2).

Overall, the dialysis population had a significantly higher prevalence of infection when stratified by 20 -year age categories than the reference group (Mantel-Haenszel weighted OR, 5.03; CI, 1.50-17.68). There were no significant differences in infection associated with sex $(2.72 \%$ male subjects vs. $2.78 \%$ female subjects; OR, 0.98 ; CI, 0.17-5.32) or race (3.37\% African-American vs. $0.00 \%$ other; $P=.36$, Fisher's exact test).

\section{Association with Chronic Disease}

JHH proteinuria group. Crude analyses between demographic and clinical features and hantavirus infection indicated that hypertension, stroke, and hypertensive renal disease were associated with the presence of hantavirus antibodies (table 3 ). Conditional logistic regression analysis demonstrated significant correlations among these three variables, and hypertension and stroke did not meet the criterion for inclusion in the final model.

Race was included in the final model a priori as a factor known to be confounded with hypertensive disease. By using conditional logistic regression and controlling for race (table 3), hantavirus-seropositive individuals had a significantly higher frequency of hypertensive renal disease (OR, 16.19; CI, 3.05-86.00) than did seronegative hospital patients with proteinuria (table 3 ). There was no overall difference in the frequency of occurrence of the two major chronic diseases

Table 3. Crude and adjusted odds ratios (ORs) and 95\% confidence intervals (CIs) for variable obtained from Johns Hopkins Hospital proteinuria group analyzed for their associations with hantavirus antibody.

\begin{tabular}{|c|c|c|}
\hline Variable & Crude OR & $\mathrm{CI}$ \\
\hline Residence (city vs. other) & 1.24 & $0.43-3.60$ \\
\hline Sex (male vs. female) & 0.81 & $0.21-3.16$ \\
\hline Hypertension (present vs. absent) & 5.20 & $1.11-24.41$ \\
\hline \multicolumn{3}{|l|}{ Renal disease (none vs. any } \\
\hline etiology) & 1.27 & $0.92-1.76$ \\
\hline Stroke (present vs. absent) & 3.63 & $1.34-9.86$ \\
\hline \multicolumn{3}{|l|}{$\begin{array}{l}\text { Diabetes mellitus (present vs. } \\
\text { absent) }\end{array}$} \\
\hline \multirow{3}{*}{$\begin{array}{l}\text { Hypertensive renal disease } \\
\text { (present vs. absent) } \\
\text { Race (African-American vs. } \\
\text { other) }\end{array}$} & 20.50 & $6.03-69.70$ \\
\hline & 3.33 & $0.94-11.82$ \\
\hline & Adjusted OR & $\mathrm{CI}$ \\
\hline \multicolumn{3}{|l|}{ Hypertensive renal disease } \\
\hline $\begin{array}{l}\text { Race (African-American vs. } \\
\text { other)* }\end{array}$ & 1.26 & $0.28-5.79$ \\
\hline
\end{tabular}

* Included in conditional logistic regression model. 
reported for this group, diabetes mellitus (OR, 0.42; CI, $0.14-1.28$ ) and renal disease (OR, 1.27; CI, 0.92-1.76), indicating the specificity of the association. No other clinical or demographic variable, including residence, was associated with hantavirus infection (table 3).

Dialysis group. Primary diagnoses for the cause of endstage renal disease were available for all 328 patients who were using the four hemodialysis units. In this population, the leading causes of end-stage renal disease were hypertension $(40.7 \%)$ and diabetes mellitus (29.0\%). Other significant causes of renal disease were glomerulonephritis due to various causes $(7.6 \%)$, obstructive uropathies $(3.2 \%)$, polycystic disease (2.6\%), and intravenous drug use (2.2\%). There were no statistical differences by race, sex, or primary disease diagnosis (based on hypertension, diabetes mellitus, or other) between those who participated in the study and those who did not $(P>.50$ in all tests).

All 7 seropositive patients had hypertensive renal disease as the primary diagnosis underlying their end-stage renal disease $(P=.0018$, Fisher's exact test). Overall, among the hypertensive population with end-stage renal disease, $6.5 \%$ $(7 / 109)$ were seropositive for a ratborne hantavirus. There was no significant difference $(t=1.84 ; P>.05)$ in the ages of patients with hypertensive renal disease (mean \pm SD, $57.1 \pm$ 15.4 years) and patients with renal disease due to other causes $(54.1 \pm 14.4$ years $)$.

\section{Discussion}

The data presented here complement our previous report on the association between hantavirus infection and a specific chronic renal disease [14]. Although the data are associational and cannot address relevant factors, such as the temporal relationship between infection and the development of renal disease, they do support the hypothesis of a causal relationship between infection with a ratborne hantavirus and the development of hypertensive renal disease. First, the strength of association between hantavirus antibody and hypertensive renal disease is high, resulting in an OR of 16.19 in the proteinuric patient group and a significant association $(P=.0018)$ in the dialysis group. Second, the association with hypertensive renal disease is consistent across both patient groups. Finally, the association between hantavirus antibody and hypertensive renal disease was specific to this diagnosis and unrelated to other chronic renal disease.

Hantavirus infection in rodents in the United States was demonstrated shortly after the isolation of prototype Hantaan virus nearly a decade ago $[29,30]$. Several hantaviruses have been isolated from different rodent species and from varied geographic sites in the continental United States [48]. Subsequent serologic surveys documented human infection by hantaviruses in US residents [7, 9-12]. However, no definite acute cases of HFRS have been reported, although disease consistent with HFRS has been noted in 3 seroconverting patients among the JHH proteinuria group [31].
In the absence of well-defined domestic cases of HFRS, various hypotheses have been proposed to explain the reasons for global variation in disease patterns. These potential explanations include that infection by domestic strains of hantaviruses may be less virulent and produce subclinical or atypical disease and that the frequency of infection may be so low that the few cases of disease go unrecognized. Although there are increasing data from restriction pattern analyses and sequence comparisons demonstrating strain variation among hantaviruses, little information is available to link these patterns to HFRS cases of differing severity [32, 33].

However, serologic surveys do provide insights on the level of hantavirus infection in various geographic locations. Our current and previous studies demonstrate that overall hantavirus infection rates are lower in Baltimore than in areas endemic for HFRS. Antibody prevalence in the reference group $(0.25 \%)$ is an order of magnitude lower than has been reported from cross-sectional surveys from either European (7.9\% in Sweden [34]) or Asian (3.8\% in Korea [35]) HFRS-endemic locations. These comparisons suggest that lower domestic exposure may contribute to the difficulties in recognizing acute disease if it occurs. However, the data from Baltimore are conservative estimates of infection, as they are based on results confirmed by PRN tests, while results from other locations are based solely on indirect fluorescent antibody tests or ELISA.

The pattern of infection in Baltimore also differs somewhat from surveys of HFRS cases from regions endemic for the disease, indicating that the epidemiology of transmission also may vary. In Baltimore, there was no difference in antibody prevalence between male and female subjects in any of the groups surveyed. Cases of HFRS typically show a male bias of 5-6:1 in HFRS-endemic locations, presumably reflecting occupational exposures [34-36], although the distribution of hantavirus antibody may be less disparate [35]. This difference suggests that exposure in inner-city populations to ratborne hantaviruses may occur in or near residences, rather than at the workplace [37]. As such, the primary at-risk group in the United States may be urban residents rather than rural populations, as is the pattern in HFRS-endemic locations [37].

Although background antibody prevalence was low, the JHH proteinuria group had a roughly threefold increase in infection rate compared with that of the age-stratified reference group. As proteinuria is a consistent clinical feature of HFRS, such a finding suggested an association between infection with a hantavirus and some acute renal dysfunction. However, $\sim 75 \%$ of the seropositive patients in the proteinuria group had serologic tests on paired sera collected over periods of weeks that revealed unchanging titers (unpublished data). This indicated their antibody was presumably the result of infection in the past, and their current proteinuria, if related to hantavirus infection, was a manifestation of long-term or chronic disease.

The observation that hantavirus infection was also three- 
fold higher among the patients with proteinuria than in the internal reference group tested for UTP but without proteinuria is consistent with the association of hantavirus infection and renal dysfunction. It appears unlikely that the association is an artifact of the selection process, as seropositive subjects did not differ from seronegative subjects in any demographic characteristic, and the overall prevalence of chronic renal disease due to any factor did not differ between the two groups (table 3). The absence of any indicative demographic factor, including area of residence and occupation, suggests that socioeconomic factors did not differ between the groups. However, it is likely that exposure to rats per se is linked to economic conditions [37].

The statistical association of hantavirus infection with chronic renal disease also is consistent with our long-term observations of the 3 patients from the proteinuria population who showed changing antibody titers, indicating seroconversion following acute hantavirus infection (unpublished data). Two of the 3 patients were subsequently noted to have evidence of chronic renal dysfunction (serum urea nitrogen $>22 \mathrm{mg} / \mathrm{dL}$; serum creatinine $>1.2 \mathrm{mg} / \mathrm{dL}$ ) for $>1$ year, and 1 of these patients developed end-stage renal disease requiring maintenance hemodialysis. The patient had a diagnosis of hypertensive renal disease determined independently of serologic status.

The consistent finding that distinguishes between the hantavirus antibody-positive patients and the uninfected patients is the association with hypertensive renal disease. Nearly $75 \%$ of the infected JHH proteinuria group and all of the seropositive dialysis population had this diagnosis as the underlying cause of their renal disease. Hantaviruses are known to preferentially infect vascular endothelial cells [38] and possibly renal tubular epithelium [39]. Acute vascular endothelial damage is recognized as the major cause of pathology in HFRS [40]. Damage to these target cells could produce the basic lesions resulting in the observed renal dysfunction in acute cases. Our data support a hypothesis that these lesions result in permanent vascular or tubular damage that contributes to the later development of hypertensive renal disease.

Previously, most studies have reported complete although protracted recovery from HFRS. Exceptions are the reports in the Russian literature indicating $9.4 \%$ of 85 patients developed "elevated arterial pressure" 1-10 years after acute HFRS [17], and a study by Rubini et al. [15]. They noted that 2-5 years after apparent recovery from HFRS, 7 of 13 patients had acquired hyposthenuria, and 2 of 13 had developed hypertensive vascular disease. In addition, they reported 1 case of chronic glomerulonephritis and 2 cases of pyelonephritis among 31 cases after presumptive recovery. Most recently, Kleinknecht and Rollin [41] have observed the development of hypertension in 2 patients after HFRS.

Other authors have not highlighted findings suggestive of chronic renal sequelae following acute HFRS [42, 43]. Only Lahdevirta's study [42] provides sufficient detail to reexam- ine this issue. His data (table 21 in [42]) show that $\sim 70 \%$ of his patients in follow-up from HFRS were hypertensive (diastolic $>89 \mathrm{~mm} \mathrm{Hg}$ ), and $20 \%$ of the patients had diastolic blood pressures of $\geqslant 95 \mathrm{~mm} \mathrm{Hg}$. Nearly $30 \%$ had decreased renal function. More recent prospective studies of smaller numbers of patients from areas endemic for HFRS also show that $10 \%-15 \%$ of patients subsequently develop persistent renal dysfunction and essential hypertension [44]. An increased prevalence of hantavirus antibody in patient populations with renal disease also has been reported from countries where HFRS is rare or unreported, such as Ireland [45]. As these studies involve different hantaviruses (Hantaan, Seoul, and Puumala), the occurrence of chronic renal disease in a proportion of individuals appears to be a common characteristic of hantavirus infection, whether or not acute disease is apparent.

If these results are confirmed, they would suggest that some fraction of the substantial number of cases of hypertensive renal disease and resulting hypertension in the United States may be of infectious origin. Domestic exposure to ratborne hantaviruses would presumably be greatest in the inner cities of the United States [37]. However, the problem could be global, given the worldwide distribution of Seoul virus and Rattus species [46]. Future research efforts should focus on confirming this observed association in other populations and on prospective follow-up in HFRS-endemic locations of large numbers of confirmed HFRS patients over periods sufficient for establishing a diagnosis of chronic renal disease.

\section{References}

1. LeDuc JW. Epidemiology of hemorrhagic fever viruses. Rev Infect Dis 1989;1 1(suppl 4):S730-5.

2. van Ypersele de Strihou C, van der Groen G, Desmyter J. Hantavirus nephropathy in Western Europe: ubiquity of hemorrhagic fevers with renal syndrome. Adv Nephrol Necker Hosp 1986;1 15:143-72.

3. Wong TW, Chan YC, Joo YG, Lee HW, Lee PW, Yanagihara R. Hantavirus infections in humans and commensal rodents in Singapore. Trans R Soc Trop Med Hyg 1989;83:248-51.

4. Childs JE, Korch GW, Glass GE, LeDuc JW, Shah KV. Epizootiology of hantavirus infections in Baltimore; isolation of a virus from Norway rats, and characteristics of infected rat populations. Am J Epidemiol 1987;126:55-68.

5. LeDuc JW, Smith GA, Johnson KM. Hantaan-like viruses from domestic rats captured in the United States. Am J Trop Med Hyg 1984;33:992-8

6. Lee PW, Amyx HL, Yanagihara R, Gajdusek DC, Goldgaber D, Gibbs CJ Jr. Partial characterization of Prospect Hill virus isolated from meadow voles in the United States. J Infect Dis 1985;152:826-9.

7. Tsai TF, Bauer SP, Sasso DR, et al. Serological and virological evidence of a Hantaan virus-related enzootic in the United States. J Infect Dis 1985;152:126-36.

8. Baek LJ, Yanagihara R, Gibbs CJ Jr, Miyazaki M, Gajdusek DC. Leakey virus: a new hantavirus isolated from Mus musculus in the United States. J Gen Virol 1988;69:3129-32.

9. Forthal DN, Bauer SP, McCormick JB. Antibody to hemorrhagic fever with renal syndrome viruses (hantaviruses) in the United States. Am J Epidemiol 1987;126:1210-3. 
10. Childs JE, Glass GE, Korch GW, et al. Evidence of human infection with a rat-associated hantavirus in Baltimore, Maryland. Am J Epidemiol 1988; $127: 875-8$.

11. Childs JE, Glass GE, Ksiazek TG, Rossi CA, Oro JG, LeDuc JW. Human-rodent contact and infection with lymphocytic choriomeningitis and Seoul viruses in an inner-city population. Am J Trop Med Hyg 1991;44:117-21.

12. Yanagihara $\mathrm{R}$, Chin $\mathrm{CT}$, Weiss MB, et al. Serological evidence of Hantaan virus infection in the United States. Am J Trop Med Hyg 1985;34:396-9.

13. Yanagihara R, Gajdusek DC. Hemorrhagic fever with renal syndrome: global epidemiology and ecology of hantavirus infections. In: de la Maza LM, Peterson EM, eds. Medical virology VI. New York: Elsevier, 1987:171-214

14. Glass GE, Childs JE, Watson AJ, LeDuc JW. Association of chronic renal disease, hypertension, and infection with a rat-borne hantavirus. Arch Virol 1990;suppl 1:69-80.

15. Rubini ME, Jablon S, McDowell ME. Renal residuals of acute epidemic hemorrhagic fever. Arch Intern Med 1960;106:378-87.

16. Settergren B, Trollfors B, Fasth A, Hultberg B, Norrby SR. Glomerular filtration rate and tubular involvement during acute disease and convalescence in patients with nephropathia epidemica. J Infect Dis 1990;161:716-20.

17. Sirotin BZ, Shapiro IA, Maneshin VN. Tubulo-interstitial changes in patients with a history of hemorrhagic fever with renal syndrome [in Russian translated by SCITRAN]. Terapevticheskiy Arkhiv 1989;61:91-5.

18. Cizman B, Ferluga D, Kaplan Pavlovcic S, Koselj M, Drinovec J, Avsic $\mathrm{T}$. Renal involvement in hantavirus disease. Adv Exp Med Biol 1989:252:173-80.

19. Childs JE, Korch GW, Smith GA, Terry AD, LeDuc JW. Geographical distribution and age-related prevalence of Hantaan-like virus in rat populations of Baltimore, Maryland, U.S.A. Am J Trop Med Hyg $1985 ; 34: 385-7$

20. Lähdevirta J. Clinical features of HFRS in Scandinavia as compared with East Asia. Scand J Infect Dis Suppl 1982;36:93-5.

21. Lee HW. Hemorrhagic fever with renal syndrome (Seoul virus infection). In: Lee HW, Dalrymple JM, eds. Manual of hemorrhagic fever with renal syndrome. Seoul: Korea University, 1989:36-8.

22. Tamura M. Occurrence of epidemic hemorrhagic fever in Osaka city: first cases found in Japan with characteristic feature of marked proteinuria. Biken J 1964;7:79-94.

23. Kelen GD, DiGiovanna T, Bisson L, et al. Human immunodeficiency virus infection in emergency department patients. JAMA 1989; 262:516-22.

24. ICD 9 CM: International Classification of Diseases. 9th revision. 3rd ed. New York: Practice Management Information, 1989.

25. Lee PW, Meegan JM, LeDuc JW, et al. Serologic techniques for detection of Hantaan virus infection, related antigens and antibodies. In: Lee HW, Dalrymple JM, eds. Manual of hemorrhagic fever with renal syndrome. Seoul: Korea University, 1989:75-106.

26. LeDuc JW, Ksiazek TG, Rossi CA, Dalrymple JM. A retrospective analysis of sera collected by the Hemorrhagic Fever Commission during the Korean Conflict. J Infect Dis 1990;162:1182-4.
27. SAS user's guide: statistics. 5th ed. Cary, NC: SAS Institute, 1985.

28. BMDP statistical software manual, I \& II. Berkeley: University of California Press, 1988.

29. LeDuc JW, Smith GA, Bagley LR, Hasty SE, Johnson KM. Preliminary evidence that Hantaan or a closely related virus is enzootic in domestic rodents. N Engl J Med 1982;307:624.

30. Lee PW, Amyx HL, Gajdusek DC, Yanagihara R, Goldgaber D, Gibbs CJ Jr. New haemorrhagic fever with renal syndrome-related virus in indigenous wild rodents in the United States. Lancet 1982;2:1405.

31. Glass GE, Childs JE, Watson AJ, LeDuc JW. Correlates of hantaviral infection in patients from Baltimore, MD, USA [abstract 400]. In: Program and abstracts of the 40th annual meeting of the American Society of Tropical Medicine and Hygiene (Boston). Atlanta: ASTMH, 1991.

32. Xiao SY, Chu YK, Knauert FK, Lofts R, Dalrymple JM, LeDuc JW. Comparison of hantavirus isolates using a genus reactive primer pair polymerase chain reaction. J Med Virol 1992;33:277-82.

33. Arthur RR, Lofts R, Glass GE, LeDuc JW, Childs JE. Grouping of hantaviruses by $\mathrm{S}$ genome segment PCR and amplification of viral RNA from wild-caught rats. Am J Trop Med Hyg 1992;47:210-24.

34. Niklasson B, LeDuc JW. Epidemiology of nephropathia epidemica in Sweden. J Infect Dis 1987;155:269-76.

35. Lee HW. Korean hemorrhagic fever. Prog Med Virol 1982;28:96-113.

36. Nysrtöm K. Incidence and prevalence of endemic benign (epidemic) nephropathy in AC County, Sweden, in relation to population density and prevalence of small rodents. Umeå University Medical Dissertations (New Series) 1977;30:1-92.

37. Childs JE, Glass GE, LeDuc JW. Rodent sightings and contacts in an inner-city population of Baltimore, Maryland, U.S.A. Bull Soc Vector Ecol 1991;16:245-55.

38. Yanagihara R, Silverman DJ. Experimental infection of human vascular endothelial cells by pathogenic and nonpathogenic hantaviruses. Arch Virol 1990;111:281-6.

39. Kim S, Kang ET, Kim YG, et al. Localization of Hantaan viral envelope glycoproteins by monoclonal antibodies in renal tissues from patients with Korean hemorrhagic fever. Am J Clin Pathol 1992 (in press).

40. Powell GM. Hemorrhagic fever: a study of 300 cases. Medicine (Baltimore) 1954;33:97-153

41. Kleinknecht D, Rollin PE. Hypertension after hemorrhagic fever with renal syndrome. Nephron 1993;61:121.

42. Lähdevirta J. Nephropathia epidemica in Finland. Ann Clin Res 1971;3(suppl 8):1-154.

43. Lee HW, van der Groen G. Hemorrhagic fever with renal syndrome. Prog Med Virol 1989;36:62-102.

44. LeDuc JW, Childs JE, Glass GE. The hantaviruses, etiologic agents of hemorrhagic fever with renal syndrome: a possible cause of hypertension and chronic renal disease in the United States. Annu Rev Public Health 1992;13:78-98.

45. Davies EA, Rooney PJ, Coyle PV, Simpson DI, Montgomery IW, Stanford CF. Hantavirus and Leptospira [letter]. Lancet 1988;2:460-1.

46. LeDuc JW, Smith GA, Childs JE, et al. Global survey of antibody to Hantaan-related viruses among peridomestic rodents. Bull WHO 1986;64:139-44. 